\section{Tragedy of the commons in Melipona bees}

\author{
Tom Wenseleers ${ }^{\star}$ and Francis L. W. Ratnieks \\ Laboratory of Apiculture and Social Insects, Department of Animal \\ and Plant Sciences, University of Sheffield, Sheffield S10 2TN, UK \\ * Author and address for correspondence: Laboratory of Entomology, \\ University of Leuven, Naamestraat 59, B-3000 Leuven, Belgium \\ (tom.wenseleers@bio.kuleuven.ac.be).
}

Recd 05.11.03; Accptd 22.12.03; Published online 03.03.04

In human society selfish use of common resources can lead to disaster, a situation known as the 'tragedy of the commons' (TOC). Although a TOC is usually prevented by coercion, theory predicts that close kinship ties can also favour reduced exploitation. We test this prediction using data on a TOC occurring in Melipona bee societies.

Keywords: caste conflict; tragedy of the commons; stingless bees; Melipona

\section{INTRODUCTION}

Since influential analysis by Hardin (1968) of the 'tragedy of the commons' (TOC), the consensus has been that coercive management is necessary to prevent overexploitation of common resources such as fish stocks or grazing land (Hardin 1998; Ostrom 1999). Hardin (1968) argued that rational individuals benefit from increasing their share, even if this depletes the resource on which they depend. In his view, the only way to curb individual selfishness and prevent a TOC was by 'mutual coercion mutually agreed upon' (Hardin 1968). Models developed by evolutionary theorists (Hamilton 1964; Frank 1995, 1998), however, show an additional mechanism. If the level of exploitation is heritable and groups are composed of kin, a rational or 'evolutionary stable' exploitation rate will evolve that is inversely related to genetic relatedness (Frank 1995, 1998). However, this prediction has never been tested because in most societies or family groups kinship benefits co-occur with coercion (Mock \& Parker 1998), making it impossible to determine their relative contributions. We test the effects of kinship on the outcome of a TOC that, uniquely, cannot be prevented by coercion. It concerns the exploitation of a common resource-the workforce-in Melipona stingless bee societies.

In highly eusocial bees, such as honeybees and stingless bees, all work is carried out by morphologically specialized worker individuals that, like queens, are female (Wilson 1971). The workforce is necessary for colony reproduction, whether by rearing males or by establishing new colonies via colony fission, in which a queen and a swarm of workers establish a new nest. Becoming a queen, however, is potentially more rewarding than becoming a worker since queens have greater reproductive potential than workers and only queens can ever head daughter colonies (Bourke \& Ratnieks 1999; Wenseleers et al. 2003). So why do more females not attempt to develop as queens rather than workers? In TOC terms, what prevents the common resource-the workforce-from being exploited by larvae selfishly choosing to develop into queens? As in Hardin's 'mutual coercion mutually agreed upon', a TOC is usually prevented by enforcement (Bourke \& Ratnieks 1999). In honeybees (Apis) and most stingless bees (Trigonini), queens are larger than workers (Wilson 1971). As a result, the adult workers can prevent larval females from developing into queens by controlling their access to food ('nutritional caste determination'; figure 1). As expected from theory, colonies in these taxa rear few queens, just enough to permit seasonal swarming or supersedure of a failing mother queen (Wenseleers et al. 2003). For example, in the honeybee Apis mellifera and in the trigonine bee Tetragonisca angustula, only ca. $0.02 \%$ of all females develop into queens over a single season (Winston 1987; van Veen \& Sommeijer 2000).

Melipona stingless bees are a unique exception to this pattern (Ratnieks 2001; Wenseleers et al. 2003). In Melipona, the adult workers have little power to control the caste fate of developing females because queens and workers are the same size, and are reared in identical sealed cells (Engels \& Imperatriz-Fonseca 1990; figure 1). This gives individual female larvae the power to determine their own fate (Bourke \& Ratnieks 1999; Ratnieks 2001; Wenseleers et al. 2003; figure 1). Theory shows that in the pursuit of their individual interests, self-determination should result in a TOC in which many more immature females develop into queens than are needed for swarming (Bourke \& Ratnieks 1999; Ratnieks 2001; Wenseleers et al. 2003). This general prediction is supported because Melipona colonies greatly overproduce queens (Wilson 1971; Engels \& Imperatriz-Fonseca 1990) (5-16\% of all females develop into queens; figure 2). This is costly to the colony as a whole since the excess queens serve no useful purpose and are swiftly executed by the workers after they emerge from their cells (Koedam et al. 1995; figure 1). However, inclusive fitness theory also makes more detailed predictions; in particular, that fewer females should selfishly develop into queens when the cost of queen overproduction falls on closer kin (Wenseleers et al. 2003). One major factor that affects kinship is the extent of worker reproduction. Workers can lay male eggs. When more of the colony's males are workers' sons, the cost of excess queen production is borne by more highly related individuals, namely workers' sons (nephews, $r=0.375$ ) rather than queen's sons (brothers, $r=0.25$ ). Theory predicts that queen overproduction should be reduced when more males are workers' sons (Ratnieks 2001; Wenseleers et al. 2003). We present the first test, to our knowledge, of this prediction using data on queen production in Melipona species with different degrees of worker reproduction (figure 2; see electronic Appendix A).

\section{METHODS}

\section{(a) Male parentage and caste ratios}

To test the effect of kinship on queen production we collated all available data on male parentage and female caste ratio in Melipona. A total of 32 studies and four reviews across 13 species were found. However, we only used studies where male parentage and caste ratio were known for the same population or geographical region, and were measured in either their natural environment or laboratory conditions where conditions approached natural ones as closely as possible. This produced 12 studies on four species: Melipona beecheii (three studies, all from Yucatan, Mexico), M. favosa (Tobago, West Indies), $M$. quadrifasciata (various sites, Brazil) and M. subnitida (Rio Grande do Norte, Brazil) (see tables 1, 2 in electronic Appendix A). Male production by workers and female caste ratios in these four species are 
(a)

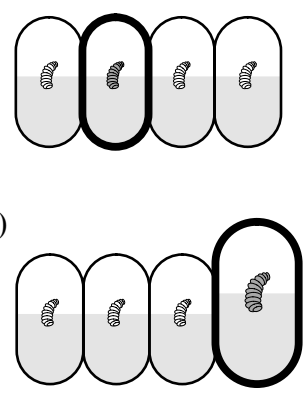

(c)

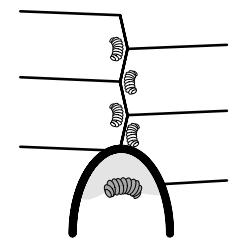

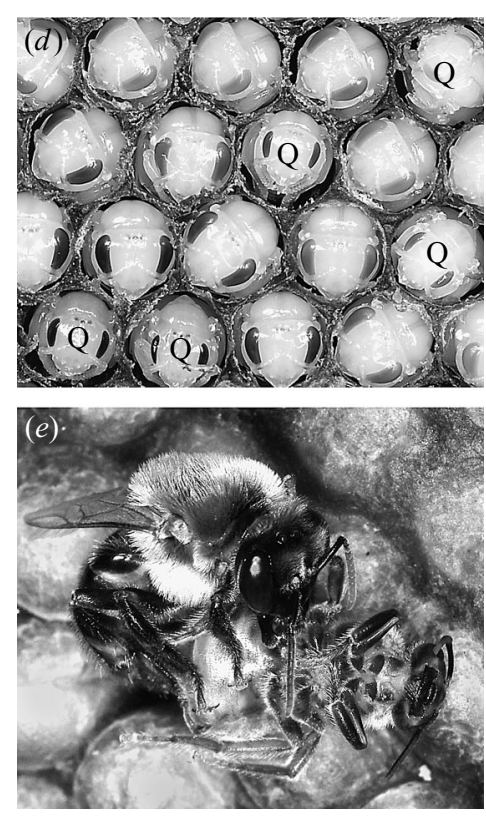

Figure 1. In Melipona bees queens are the same size as workers and develop individually in a sealed cell (bold) on a provision mass (a). This gives female larvae sufficient resources to develop into either caste. In other highly eusocial bees, Trigonini stingless bees $(b)$ and honey bees (c), the larger queens develop in special cells and their rearing is under the control of the adult workers who build and provision the cells. In Melipona, individual control of caste development results in a TOC in which many more queens are reared than are needed $((d) \mathrm{Q}$, queen pupae in cells from which cappings have been removed). Excess queens are killed by workers (left) soon after emergence (e).

summarized in figure 2. Detailed statistics and a complete list of the original studies are available in electronic Appendix A.

\section{RESULTS}

As predicted, in species where many males are workers' sons (M. favosa, Sommeijer et al. 1999; M. quadrifasciata, da Silva 1977; Tóth et al. 2002; M. subnitida, Contel \& Kerr 1976; Koedam et al. 1999), fewer females selfishly become queens (5.1-8.6\%; Kerr 1950; Koedam et al. 1999; Sommeijer et al. 2003) than in M. beecheii (15.8\%; Darchen \& Delage-Darchen 1975; Moo-Valle et al. 2001), where all males are queens' sons (Paxton et al. 2001) (see tables 1 and 2 in electronic Appendix A). In addition, queen production is lower in $M$. favosa (5.1\%), a species in which nearly all males are workers' sons (Sommeijer et al. 1999), than in M. subnitida (7.1\%; Koedam et al. 1999) and $M$. quadrifasciata (8.6\%; Kerr 1950), where 36-51\% of the males are workers' sons (see tables 1 and 2 in electronic Appendix A). The negative relationship between queen overproduction and worker reproduction is significant $(\gamma=1, Z=2.04, p=0.04)$ and supports the role of kinship in influencing a tragedy of the commons. The observed caste ratios, 5-16\%, are slightly lower than those predicted by theoretical models (14-20\%; Wenseleers et al. 2003). However, these models assume that excess queen production causes a linear reduction in total colony productivity (male and swarm production; Wenseleers et al. 2003). If the cost function were concave, a closer match between theoretical and empirical figures occurs (a)
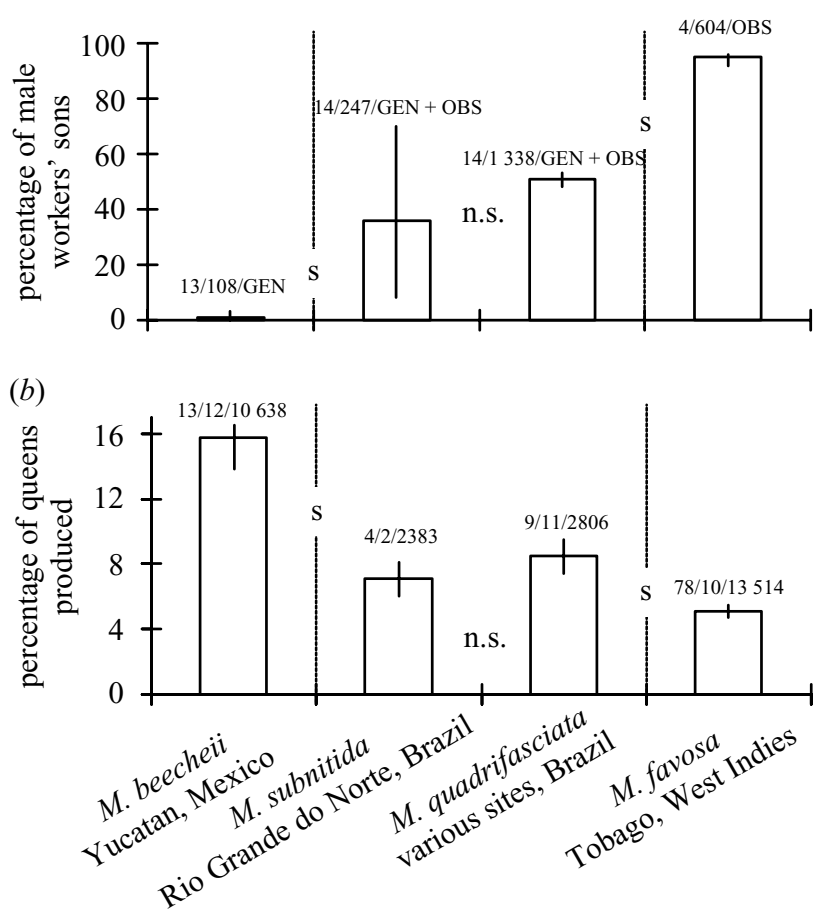

Figure 2. The effect of the colony kin structure on queen production in Melipona. Theory predicts that fewer females should selfishly develop as queens when many males are workers' sons because the cost of excess queen production is then borne by closer relatives, nephews $(r=0.375)$ rather than brothers $(r=0.25)$. This prediction is supported by levels of queen production in Melipona species with variable degrees of worker reproduction. In Melipona favosa, where (a) nearly all males are workers' sons, and $(b)$ fewer females selfishly become queens (5.1\%) than in M. beecheii (15.8\%), where all males are queen's sons. In $M$. subnitida and $M$. quadrifasciata, where $(a)$ the queen and the workers share male parentage, and $(b)$ queen production is intermediate (7.1 and $8.6 \%)$. The negative relationship between queen overproduction and worker reproduction is significant $(\gamma=1, Z=2.04, p=0.04)$. For each data point the mean, $95 \%$ binomial confidence limit and sample size are shown (number of colonies/months/individuals for queen production data and number of colonies/males for male parentage data). For the male parentage data, it is also shown whether the data come from genetic (GEN) or observational studies (OBS), or both combined (GEN + OBS). Significant $(p<0.05)$ and non-significant $(p>0.05)$ differences between data points, as indicated from a non-overlap of the confidence limits, are indicated with 's' and 'n.s.'. A detailed list of the source studies on which the comparison is based is given in electronic Appendix A.

(Wenseleers et al. 2003). Importantly, however, a negative relationship between queen production and worker reproduction is predicted by the theory irrespective of the exact shape of the cost function. Hence, relative predictions are robust and independent of detailed assumptions.

\section{DISCUSSION}

What general lessons can be learned from the way that bees resolve tragedies of the commons? The Melipona case shows that in a situation where a common resource is free to be used by all, selfish exploitation is inevitable (Hardin 1968, 1998). In this respect, Hardin's conclusion that 
'freedom in a commons brings ruin to all' remains (Hardin 1968, 1998). Not considered by Hardin (1968, 1998), however, were the effects of kinship. Our results provide the first tentative evidence, to our knowledge, that kinship can also partly reduce a TOC. This may be relevant to human society, such as in cases where common resources are shared by an extended family. However, coercion is more effective than kinship in resolving a TOC. Consider the honeybee $A$. mellifera. Because of multiple mating by queens, relatedness among offspring females is low ( $c a$. 0.30), and the optimum proportion of female larvae that should develop into queens, given the ability to do so, is very high (56\%; Wenseleers et al. 2003). However, excess queen production in honeybees is effectively prevented because the adult workers can enforce the caste fate of larvae by rearing them in distinct cells and on different foods (Winston 1987; Beekman et al. 2003; figure 1). This shows that nutritional caste determination, found in most social Hymenoptera with morphologically distinct queen and worker castes (Wilson 1971), is actually a form of social suppression that forces individuals to work for the benefit of society, even when this is against the individuals' own selfish interests. In other words, social insect workers may usually be oppressed rather than genuinely altruistic (cf. Michener \& Brothers 1974; Alonso \& Schuck-Paim 2002). In human society, social suppression is also widespread, but fortunately never reaches the point found in bees where individuals are fated, by their morphology, to work.

Alonso, W. J. \& Schuck-Paim, C. 2002 Sex-ratio conflicts, kin selection, and the evolution of altruism. Proc. Natl Acad. Sci. USA 99, 6843-6847.

Beekman, M., Komdeur, J. \& Ratnieks, F. L. W. 2003 Reproductive conflicts in social animals: who has power? Trends Ecol. Evol. 18, 277-282.

Bourke, A. F. G. \& Ratnieks, F. L. W. 1999 Kin conflict over caste determination in social Hymenoptera. Behav. Ecol. Sociobiol. 46, 287-297.

Contel, E. P. B. \& Kerr, W. E. 1976 Origin of males in Melipona subnitida estimated from data of an isozymic polymorphic system. Genetica 46, 271-279.

Darchen, R. \& Delage-Darchen, B. 1975 Contribution à l'étude d'une abeille du Mexique Melipona beecheii B. (Hymenoptère: Apide). Apidologie 6, 295-339.

da Silva, D. L. N. 1977 Estudos bionomicos em colônias mistas de Meliponinae. Bol. Zool. São Paulo 2, 7-106.

Engels, W. \& Imperatriz-Fonseca, V. L. 1990 Caste development, reproductive strategies, and control of fertility in honey bees and stingless bees. In Social insects. An evolutionary approach to castes and reproduction (ed. W. Engels), pp. 167-230. Berlin: Springer.

Frank, S. A. 1995 Mutual policing and repression of competition in the evolution of cooperative groups. Nature 377, 520-522.
Frank, S. A. 1998 The foundations of social evolution. Monographs in behavior and ecology. Princeton University Press.

Hamilton, W. D. 1964 The genetical evolution of social behaviour. Parts I \& II. F. Theor. Biol. 7, 1-52.

Hardin, G. 1968 The tragedy of the commons. Science 162, 12431244.

Hardin, G. 1998 Extensions of 'the tragedy of the commons'. Science 280, 682-683.

Kerr, W.E. 1950 Genetic determination of castes in the genus Melipona. Genetics 35, 143-152.

Koedam, D., Aguilar Monge, I. \& Sommeijer, M. J. 1995 Social interactions of gynes and their longevity in queenright colonies of Melipona favosa (Apidae: Meliponinae). Neth. F. Zool. 45, 480-494.

Koedam, D., Contrera, F. A. L. \& Imperatriz-Fonseca, V. L. 1999 Clustered male production by workers in the stingless bee Melipona subnitida Ducke (Apidae, Meliponinae). Insectes Soc. 46, 387-391.

Michener, C. D. \& Brothers, D. J. 1974 Were workers of eusocial Hymenoptera initially altruistic or oppressed? Proc. Natl Acad. Sci. USA 71, 671-674.

Mock, D. W. \& Parker, G. 1998 The evolution of sibling rivalry. Oxford University Press.

Moo-Valle, H., Quezada-Euan, J. J. G. \& Wenseleers, T. 2001 The effect of food reserves on the production of sexual offspring in the stingless bee Melipona beecheii (Apidae, Meliponini). Insectes Soc. 48, 398-403.

Ostrom, E. 1999 Governing the commons. Cambridge University Press.

Paxton, R. J., Ruhnke, H., Shah, M., Bego, L. R., Quezada-Euan, J. J. G. \& Ratnieks, F. L. W. 2001 Social evolution in stingless bees: are the workers or is the queen in control of male production? In II Seminario Mexicano sobre abejas sin aguijón (ed. J. J. G. Quezada-Euan), pp. 104-107. Yucatán, México: Universidad Autónoma de Yucatán, Mérida.

Ratnieks, F. L. W. 2001 Heirs and spares: caste conflict and excess queen production in Melipona bees. Behav. Ecol. Sociobiol. 50, 467-473.

Sommeijer, M. J., Chinh, T. X. \& Meeuwsen, F. J. A. J. 1999 Behavioural data on the production of males by workers in the stingless bee Melipona favosa (Apidae, Meliponinae). Insectes Soc. 46, 92-93.

Sommeijer, M. J., de Bruijn, L. L. M., Meeuwsen, F. J. A. J. \& Martens, E. P. 2003 Natural patterns of caste and sex allocation in the stingless bees Melipona favosa and M. trinitatis related to worker behaviour. Insectes Soc. 50, 38-44.

Tóth, E., Strassmann, J. E., Nogueira-Neto, P., Imperatriz-Fonseca, V. L. \& Queller, D. C. 2002 Male production in stingless bees: variable outcomes of queen-worker conflict. Mol. Ecol. 11, 2661-2667.

van Veen, J. W. \& Sommeijer, M. J. 2000 Colony reproduction in Tetragonisca angustula (Apidae, Meliponini). Insectes Soc. 47, 7075.

Wenseleers, T., Ratnieks, F. L. W. \& Billen, J. 2003 Caste fate conflict in swarm-founding social Hymenoptera: an inclusive fitness analysis. F. Evol. Biol. 16, 647-658.

Wilson, E. O. 1971 The insect societies. Cambridge, MA: Harvard University Press.

Winston, M. L. 1987 The biology of the honey bee. Cambridge, MA: Harvard University Press.

Visit www.journals.royalsoc.ac.uk and navigate to this article through Biology Letters to see the accompanying electronic appendix. 